\title{
Investigating the Role of Organizational Culture in Facilitating Continuous Improvement within Saudi Non-profit Organizations
}

\author{
Sulaiman ALMAIMAN and Patrick MCLAUGHLIN \\ Cranfield University, Cranfield, MK43 OAL, UK \\ Correspondence should be addressed to: Sulaiman ALMAIMAN; s.maiman@mail.com \\ Received date: 15 March 2018; Accepted date: 14 May 2018; Published date: 19 July 2018. \\ Academic Editor: Sock Lee Ching \\ Copyright (C) 2018. Sulaiman ALMAIMAN and Patrick MCLAUGHLIN .Distributed under Creative \\ Commons CC-BY 4.0
}

\begin{abstract}
It has been confirmed that organizational culture has a significant impact on facilitating continuous improvement, although it is not clear yet how this impact can be achieved. On the other hand, nonprofit organizations struggle mainly in sustaining resources and increasing the quality of the services they provide. Several recent studies have confirmed the crucial role of organizational culture in implementing operational management approaches. However, answering the question of "how" is still awaiting a clear road map. Nonetheless, nonprofit organizations contribute remarkably to economies and civilisation. They deserve research attention, and studies done on continuous improvement suggest it to be holistically beneficial. Hence, this paper shows an empirical investigation that selected Saudi nonprofit organizations for their social setting to explore the influence of organizational culture on facilitating continuous improvement. The approach of grounded theory has been employed, using qualitative data, to construct a reality based on participant perspectives. The thirty-one interviews that were conducted at thirteen organizations revealed many lower level cultural aspects. These aspects were evolved, during five focus groups, into six higher-level themes. The findings can be used by leaders to create desired change.
\end{abstract}

Keywords: Organizational Culture, Continuous Improvement, Nonprofit Originations, Saudi Arabia

\section{Introduction}

Although overwhelming challenges face nonprofit organization (NPOs), they increasingly play a significant role in economies and well-being (Alshammari et al.
2014). On the other hand, continuous improvement (CI) is considered to be an important driver towards operational excellence (Iberahim et al. 2016). The literature has confirmed that CI is only successful when there is an appropriate

Cite this Article as: Sulaiman ALMAIMAN and Patrick MCLAUGHLIN (2018)," Investigating the Role of Organizational Culture in Facilitating Continuous Improvement within Saudi Non-profit Organizations", Inurnal of Human Resnurres Manaoement Research. Vol. 2018 (2.018). Article In 72.4461 
organizational culture (van Dun et al. 2017) but the question of 'how' has still not received sufficient research. Furthermore, the main body of research in this field has been carried out in developing countries and other sectors, which suggests Saudi NPOs as a novel research context for this study. Saudi Arabia is a member of the G20, and its GDP exceeded 0.7 trillion USD in 2014 (The World Bank 2018). Saudi Arabia is a significant competitor in several areas; for instance, in 2017 it was one of the ten countries in control of the world's energy supplies (USNews 2018). It has been moving seriously, recently, toward change. In the period 20152016, it jumped five ranks in the transparency index, which is calculated for 180 countries, to occupy $11^{\text {th }}$ place among the G20 (Transparency International 2017). It also has a fast-growing economy, and its NPO sector increased by $20 \%$ between 2015 and 2016 (ICNL 2016). An ambitious part of its vision is to raise the nonprofit sector's contribution to the GDP by 2030 from its current less than $1 \%$ to $5 \%$ (Council of Economic and Development Affairs 2016). Therefore, it is crucial to increase and sustain the NPO's capabilities to achieve this ambitions vision. Serious efforts should include leading cultural change within NPOs to facilitate drivers of operational excellence. One of these drivers is $\mathrm{CI}$, which has been proving its impact in other sectors, particularly manufacturing.

The nonprofit sector is a major component in countries' economies. Studies show that the impact of NPOs has increased significantly around the world. Salamon et al. (Salamon et al. 2013) provide indicators of NPOs' impact worldwide. They report indicators that compare the nonprofit sector with other sectors by the size of the labour force and share of GDP. Thirteen countries participated in their study, as shown in Error! Reference source not found. below, which shows that NPOs are key players in economies. In share of work force, NPOs are in sixth place (7.4\%), right after the construction sector and, remarkably, above the transportation sector. Fifteen countries were then used to compare their GDP breakdowns by sector. The table below shows the average shares in the economies for the sectors, and the NPO sector comes in fifth place, with a contribution to GDP of $4.5 \%$ (Salamon et al. 2013).

\section{Research Problem}

Influenced by the current dynamic and complex operating environment, NPOs are increasingly concerned about their organizational sustainability (Claeyé \& Jackson 2012). NPOs suffer from uncertainty in government funding and the decline of private donations due to economic difficulties, in addition to growing competition within and outside the sector, rendering the survival of NPOs a more difficult task (Al-Tabbaa et al. 2013). The literature reports that organizations can become more competitive by establishing the right culture (Pun 2001). If the wrong culture exists, no matter what the efforts to promote continuous improvement are, few changes are likely to be accomplished (Ahmed et al. 1999). Conversely, not focusing on organizational culture affects the longevity of improvements and, hence, competitiveness (Testani \& Ramakrishnan 2012). Continuous improvement has the advantage for smaller organizations of not requiring much outlay or expertise (Bessant et al. 1994), thus it may help NPOs as well. Meanwhile, Saudi Arabia has not received much attention in the literature in this regard, despite its unique situation (Ovidiu-Iliuta 2014; Givens 2012; Alshammari et al. 2014; Montagu 2010). Therefore, this research investigates which aspects of organizational culture would facilitate continuous improvement within this context.

\section{Research Settings}

It is required for qualitative research to define the research context (Holliday 2016), which is the nonprofit sector in Saudi Arabia for this study.

\section{Overview on Saudi Context}

The Kingdom of Saudi Arabia is the largest country on the Arabian Peninsula, which occupies $80 \%$ of the total area, with a population that exceeded 32 million in 2017 and $70 \%$ of them was under the age of 30 (Vietor \& Sheldahl-Thomason 2018). Saudi culture has as its recognised religion Islam, a 
religion that today has an estimated 1.8 billion adherents (as of 2015), about 24\% of the world's population. The number of adherents is expected to reach 2.2 billion by 2030 (Pew Research Center 2017). Recently, Saudi Arabia was a significant competitor in several areas; for instance, in 2017 it was one of the ten countries in control of the world's energy supplies (USNews 2018). It has been moving seriously, recently, toward change, where it jumped five ranks within a year 2015-2016 in the transparency index among 180 countries to be the $11^{\text {th }}$ country among G20 (Transparency International 2017). Islam is assumed to shape the mentality and behaviour of the Saudi people and their Arab traditions (Bjerke \& Al-Meer 1993), pervading Saudi life (Hofstede 1991). Saudi Arabia, the birthplace of Islam, is one of the world's most religious countries (Al Ahwal et al. 2016). Islam promotes a set of moral values and social behaviours based on the text of the Qur'an and sayings of the prophet Mohammad, peace be upon him (Kabasakal \& Bodur 2002). However, it should be noted that not everything in an Islamic country necessarily represents Islamic values (Albassam \& Ntim 2017).

\section{Saudi National Culture}

Saudi culture, which nourishes the NPOs studied in this research, has Islam as its recognised religion, a religion that, today, has an estimated 1.8 billion adherents (as of 2015), approximately $24 \%$ of the world's population. The number of adherents is expected to reach 2.2 billion by 2030 (Pew Research Center 2017). Islam is assumed to shape the mentality and behaviour of the Saudi people and their Arab traditions (Bjerke \& Al-Meer 1993), pervading Saudi life (Hofstede 1991). Saudi Arabia, the birthplace of Islam, is one of the world's most religious countries (Al Ahwal et al. 2016). Islam promotes a set of moral values and social behaviours based on the text of the Qur'an and sayings of the prophet Mohammad, peace be upon him (Kabasakal \& Bodur 2002). However, it should be noted that not everything in an Islamic country necessarily represents Islamic values. Saudi national culture has been discovered through the lens of Hofstede et al. six-dimensional model (2010), who believe that dimensions were identified as existing at the individual level, as well as at the national level. According to Hofstede et al. (2010), Saudi culture has revealed the following scores for each dimension. The power distance in Saudi Arabia is very high (95) and tends to be more centralised, where people accept a hierarchical order with no need for further justification. In the second dimension (individualism), the score was low (25), which shows that Saudi Arabia is considered a collectivistic society, where loyalty in a collectivist culture is paramount, and overrides most other societal rules and regulations. Masculinity in Saudi society seems to be relatively high (60). In masculine countries the emphasis is on equity, competition and performance and conflicts are resolved by fighting them out. Saudi culture has a preference for avoiding uncertainty (80). Countries exhibiting high uncertainty avoidance maintain rigid codes of belief and behaviour. Saudi culture has revealed low score in long term orientation dimension (36), which exhibits great respect for traditions and a focus on achieving quick results. In the last dimension (indulgence), Saudi Arabia has achieved 52, which does not point to a clear preference on this dimension (Hofstede et al. 2010).

\section{Saudi Nonprofit Sector}

The ministry in Saudi Arabia which regulates the affairs of NPOs is the Ministry of Labour and Social Development (MLSD). The ministry categorises NPOs into two types: charities and foundations. Of the 900 organizations registered as NPOs in April 2016, 736 were charities and 164 were foundations (ICNL 2016). According to government regulations (MLSD 2017), the few legal differences between these two categories. First, private foundations can be established individually or by groups, whereas charities may be established only by groups of at least 20 volunteers. Second, foundations should generally support projects which are operated by charities; hence, they cannot benefit from government funding. Third, the detailed existing regulations issued by the MLSD are meant to guide charities alone.

Although the MLSD is responsible for the most common and officially registered NPOs, 
there are, however, other Saudi Arabian nonprofit agencies. Alternative nonprofit teams, not considered organizations, may be recruited for projects by wealthy people, and the 'Royal Foundation' may be patronised by a member of the Saudi Royal Family and supervised by the Royal Court. Some reports indicate that the real number is massively more than what is only registered in MLSD, and they suggest that the estimated number is 2,598, which is fragmentedly registered in 13 governmental authorities (King Khalid Foundation 2018). Nonetheless, this research had to count only on the main authority, which is MLSD. Moreover, there are further illustrations of Saudi NPOs that have been recently reported by King Khalid foundation (2018), which provides an up-todate indicators of Saudi NPOs. The report shows that the average annual individual contribution to NPOs is 2,769 SAR, and the total individual contributions represent 38\% of charitable organizations' income and governmental aid represent $27 \%$. The report, also, stated that the size of private endowments exceeds 300 billion SAR and public endowments exceed 54 billion SAR, which they are resources for NPO sustainability. NPOs activities are categorised into four groups: social services $47 \%$, housing and development $46 \%$, Health $5.75 \%$ and education and research $1.20 \%$ (King Khalid Foundation 2018).

\section{Existing Knowledge of the Research Question}

Based on the literature review, there have been limited articles that could be leveraged to answer the research question that investigates what aspects of culture could facilitate CI. These articles demonstrated diversity of their characteristics. These articles have revealed eight main cultural aspects to facilitate CI. The figure below shows a comparison for the most relevant articles and summarises their descriptive characteristics. This figure has highlights some gaps that can be considered in further research. The most significant aspect here is the lack of focus on some sectors, namely, nonprofit and mining. Moreover, the developing countries have not attracted sufficient research.
Date

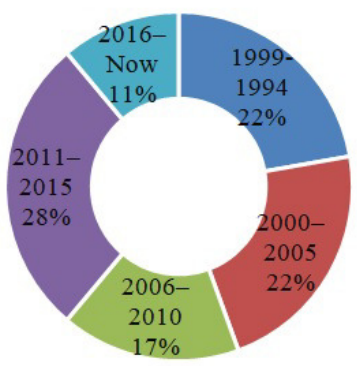

Sector

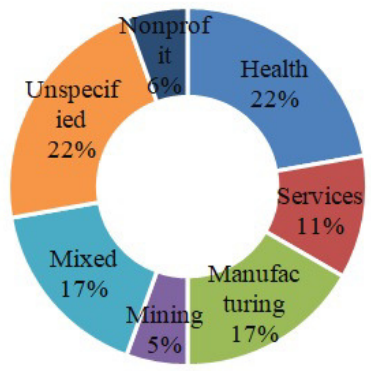

Location

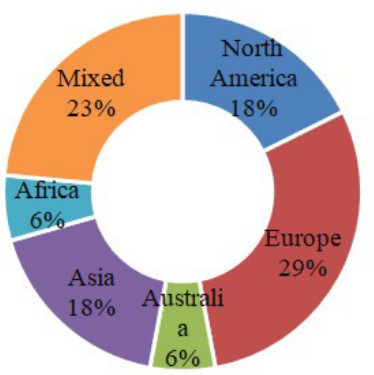

Figure 1: Descriptive analysis of the relevant articles

\section{Methodology}

Given that there is a paucity of literature on the application of CI within NPOs and the highlighted need in the literature to activate this concept in certain circumstances, an exploratory and qualitative method has been adopted as a research strategy. This was considered appropriate because the study involves an inquiry process to understand the potential of a social phenomenon (Creswell 1994), which investigates a social interaction. This suggests that social constructivism is a valid starting point. Social interactions also 
involve individuals' behaviours, and their actions need to be interpreted logically. This suggests that interpretivism is also an appropriate option (Eden \& Huxham 1996). The grounded theory approach was found to be appropriate for exploring the aspects of organizational culture that affect CI. This would suggest that an inductive approach should be used since it can evolve as the research proceeds. Further, Sackmann (Sackmann 1991) recommends the inductive approach because of the sparsity of empirically- based knowledge of culture in its 'organizational context.' The theory, then, may be discovered from the data, as Glaser and Strauss (Glaser \& Strauss 1967) developed theirs, calling it 'grounded theory'. It is also described as a set of methods that "consist of systematic, yet flexible guidelines for collecting and analysing qualitative data to construct theories 'grounded' in the data themselves" (Charmaz 2014; Faisal et al. 2011).

\section{Data Gathering and Analysis}

There was a clear diversity among the organizations and interviewees. Participants were recruited using purposive sampling with differing experiences of the phenomenon so as to explore multiple dimensions of the social processes under study, which tries to understand why CI succeed in some organizations and fail in others (Starks \& Trinidad 2007). Two phases, described briefly below, were used to gather and analyse the data. The first phase has conducted thirty-one extensive semistructured interviews, which used an issuefocused investigation to identify which aspects of organizational culture could influence CI. These interviews gradually conducted, and theoretical sampling was guided by the results of analysing the data. This phase has revealed tens of lower-level codes (cultural factors). The second phase aimed to develop these factors into higherlevel themes. The lower-level cultural factors that emerged from analysing the interviews were developed with six members of participants during five sessions of focus group discussions. It should be noted that the data were analysed with constant, constant/simultaneous comparisons with the literature. Table 3 below summarises the characteristics of the 13 organizations and the 31 participants involved in this research.

Table 1: Organization and participant characteristics

\begin{tabular}{|c|c|c|}
\hline \multicolumn{3}{|c|}{ Organization Age } \\
\hline 10 Years & 10-5 Years & $<5$ Years \\
\hline $50 \%$ & $37 \%$ & $13 \%$ \\
\hline \multicolumn{3}{|c|}{ Organization Size } \\
\hline $\begin{array}{c}>50 \\
\text { Employees }\end{array}$ & $\begin{array}{c}50-10 \\
\text { Employees }\end{array}$ & $\begin{array}{c}<10 \\
\text { Employees }\end{array}$ \\
\hline $37 \%$ & $50 \%$ & $13 \%$ \\
\hline \multicolumn{3}{|c|}{ Interviewee Age } \\
\hline$>40$ Years & $40-30$ Years & $<30$ Years \\
\hline $50 \%$ & $31 \%$ & $19 \%$ \\
\hline \multicolumn{3}{|c|}{ Interviewee Experience } \\
\hline$>10$ Years & 10-5 Years & $<5$ Years \\
\hline $44 \%$ & $25 \%$ & $31 \%$ \\
\hline \multicolumn{3}{|c|}{ Interviewee Education } \\
\hline $\begin{array}{c}\text { Higher } \\
\text { Education }\end{array}$ & $\begin{array}{c}\text { Bachelor or } \\
\text { lower }\end{array}$ & $\begin{array}{c}\text { Higher } \\
\text { Education }\end{array}$ \\
\hline $56 \%$ & $44 \%$ & $56 \%$ \\
\hline \multicolumn{3}{|c|}{ Interviewee Managerial Level } \\
\hline Top & Middle & Low \\
\hline $50 \%$ & $25 \%$ & $25 \%$ \\
\hline
\end{tabular}




\section{Findings and discussion}

The emergent aspects (higher-level themes) were based on the tens of cultural factors (lower-level codes). The following part discusses these six higher level-themes (primary source), which integrated with the cultural aspect that were extracted from the literature (secondary source), as discussed below:

\section{Driven by Values}

It has been found that being driven by values is a key aspect for successful CI stories. Although Saudi NPOs share some similar themes that could exist in another context, there were some interesting aspects in which behaviour is shaped by Islam (Bjerke \& Al-Meer 1993). Fagan (Fagan 1996) reported that religious beliefs are associated with a higher level of social support for those in need, which was a key motivation for participants to work in this sector. Being value-driven was found to be enhanced by religious teachings, and attention is paid to achieving results to obtain God's rewards for good deeds. One of the interviewees has stated that:

\footnotetext{
“.. however, in all cases we attempt to select individuals who have the same characteristics of our employees, on the whole: to be morally and religiously disciplined and to be recommended by trustworthy individuals who are well known for their righteousness and good reputations.."
}

According to the data analysis and constant comparison with the literature, the characteristics that are associated with this theme include: the courage and resolve to change for the better, graciously accepting criticism, and sharing successes with others (Harland \& Nienaber 2014; Wick 2014; Rodell et al. 2016; Harris \& Gibson 2014; Froese et al. 2016; Lussier \& Corman 2015).

The literature shows that an organization with flourishing CI has a certain set of values. These values articulate a supportive culture (Bessant et al. 1994). Organizations must believe in action and improve their capabilities of implementing proper actions (Ahmed et al. 1999). The courage to apply changes and openness to new ideas are important values associated with CI (Ahmed et al. 1999). These values result in favourable CI behaviour patterns (Dabhilkar et al. 2007). Oliver (2009) discovered that there is a correlation between higher level of CI success and CI being part of organizational culture. Other CI values include collaborative teamwork, organizational commitment, strong communication, and respect for investing in the workforce as the most valuable capital of all (Firbank 2010; Verma \& Moran 2014; Fryer \& Ogden 2014; Nguyen \& Robinson 2015; Iberahim et al. 2016).

One of the key values in $\mathrm{CI}$ is having the wherewithal to be able to hunt for future opportunities is a powerful advantage that allows early improvements and increases competitiveness capabilities. Being oriented toward the future requires a clear framework for improvement and strategic management skills (Bessant et al. 1994). Ahmed, Loh, and Zairi (Ahmed et al. 1999) reported that an orientation toward the future is guided by having common goals that all members of an organization are aware of. Iberahim et al. (Iberahim et al. 2016) argued that no organization can sustain CI practices without a clear future orientation.

Leadership has a crucial importance in terms of driving organizations by value. Ahmed, Loh, and Zairi (Ahmed et al. 1999) stated that leadership is one of the elements that builds the internal consistency that is required for CI. De Jager et al. (de Jager et al. 2004) added that local leadership is of considerable importance in determining the success or failure of $\mathrm{CI}$ implementation. Further, Oliver (Oliver 2009) discovered that there is a correlation between higher level of CI success and supportive leadership. Considering this, Huang, Rode, and Schroeder (Huang et al. 2011) recommended that managers actively assess the extent to which the national culture endorses participative leadership. In cases where this endorsement is weak, managers should consider the extent to which the organizational culture will provide 
alternative support for this type of leadership. Verma and Moran (Verma \& Moran 2014), based on the literature and input from practitioners, confirmed that leadership commitment is a key element in a culture of quality improvement, which may be developed over time to help achieve a sustainable CI culture.

\section{Creative Environment}

Nurturing a creative environment might not be possible for all Saudi NPOs since these charities focus more on spending their resources mainly on their clients. This does not allow generosity towards employee work stations or reward systems. Struggling to sustain resources was a constant concern of the participants, one that put them under pressure, which could limit space for creativity. Foundations, on the other hand, were more likely to have a creative environment since they are financially more stable and supported by their founder, most likely an individual who gained their wealth after a long journey and much experience which they then invested in setting up and operating their foundations in a more mature and more professional manner than charities are operated under. One of the interviewees has mentioned that:

".. there is an atmosphere of friendliness and brotherhood. They can have their breakfast together, they care for each other, and they are like a big family .."

According to the data analysis and constant comparison with the literature, the characteristics that are associated with this theme include: spontaneous communications, everyone participates in decisions on optimisation to raise the standards of the organization, feedback is viewed as an opportunity, and experiences with optimisation are documented to profit from them (Alnassar 2014; Fenner-Crisp \& Dellarco 2016; Phipps et al. 2013; Chang et al. 2015; Dean et al. 2014; Murante et al. 2014; Patterson et al. 2015).

People need to be motivated to undertake improvements, which leads to create a creative environment that could reduce their resistance to change (Burke 2011). A reward system has been found to be an appropriate way to facilitate CI. Ahmed, Loh, and Zairi (Ahmed et al. 1999) claimed that an organization needs to have a reward system in order to have the internal consistency necessary to support CI. Further, Firbank (Firbank 2010) concluded that a reward system is a cultural characteristic that influences CI implementation. Finally, Fryer and Ogden (Fryer \& Ogden 2014) proposed a reward system for organizational behaviours that could guide the organizational progress of CI. This type of reward system has been found to have a significant impact when applied, and it is an effective practice (Nguyen \& Robinson 2015).

\section{Encouraged Employees}

This could be the most interesting theme, one that is possibly unique for this sector. NPO employees in Saudi Arabia have shown high motivation to be working in this philanthropy sector (Bjerke \& Al-Meer 1993; Fagan 1996). Their motivations were interpreted through their humanitarian and religious values, which encourage them to consider more than their job benefits. However, some Saudi NPOs pay their employees generously and offer attractive features (especially foundations), which adds extra potential for CI to flourish. One of the interviewees revealed that:

“.. we focused on all these practical points and scheduled practical training programs for our employees.."

According to the data analysis and constant comparison with the literature, the characteristics that are associated with this theme include: employees enjoy good relations and share values that enhance performance, the organization provides constant support and training, employees are given sufficient authority, and the organization endeavours to provide its employees with job security (McMurray \& Muenjohn 2016; Rama Devi \& Phanindra 2014; Vaijayanthi \& Shreenivasan 2014; Calvasina et al. 2014; Vasavada-Oza 2016; Bouncken \& Fredrich 2016; Jurisch \& Palka 2014; Zhang \& Cao 2014; Keim et al. 2014; Akhtar et al. 2014). 
Bessant et al. (Bessant et al. 1994) declared that, in order for an organization to enable $\mathrm{CI}$, it must have an enabling infrastructure that encourages employees to implement improvements, while Shortell et al. (Shortell et al. 1995) advised leaders to allow employees to participate in improvement activities. In addition, Broekhuizen and Frericks (Broekhuizen \& Frericks 1997) found that empowerment can improve alertness in business operations and, thereby, speed up the CI process of the organization when training the entire workforce and forming CI teams. Al-Tabbaa, Gadd, and Ankrah (Al-Tabbaa et al. 2013), who compared widely-used business excellence models, found that they share a common CI thread, i.e., organizational learning that, consequently, comes through employee empowerment. Employee empowerment, according to Verma and Moran (Verma \& Moran 2014), is a fundamental element of a culture of quality improvement. Furthermore, training and learning are organizational behaviours deeply associated with $\mathrm{CI}$ and can be used to gauge and guide organizational progress toward CI. In addition, employee participation can sustain CI practices (Iberahim et al. 2016).

\section{External Interactions}

The nature of philanthropic activities involves many parties during charity projects. These parties include four main players. First, the government, which establishes and controls legislation and funds. Second, sponsors who fund the projects (the government, again, plus individuals or foundations). Third, the charities that usually run the projects. Finally, the clients, who must be satisfied with the services provided to them. Therefore, having strong and trusted connections with these external parties would have a huge impact on strengthening CI. One of the interviewees confirmed when he said:

\footnotetext{
".. when the first organisation was established, and then the idea was copied completely. This is what is called a return for us. We achieved more additional returns in the charitable work sector .."
}

According to the data analysis and constant comparison with the literature, the characteristics that are associated with this theme include: organizations strive for customer satisfaction, willing to develop partners, benefiting from the opinions of outside experts, dealing comfortably with competitors, and participating effectively in government legislation (Cárdenas \& Mantilla 2015; Kistruck et al. 2015; Humphries \& Gibbs 2015; Dixon et al. 2014; Ramakrishnan 2015; Diamandescu \& Ionita 2015).

Organizations are not isolated from the societies in which they operate. Hence, they must determine how to act properly and positively for the benefit of society and themselves. External interactions have an undesirable risk due to uncertainty, but the risk must be taken to move forward on a CI journey (Shortell et al. 1995). Risk-taking organizations have more external adaptability than conservative organizations (Ahmed et al. 1999). CI organizations must be actively involved with other entities in society in order to be key players in preparing for better and easer CI implementation (Firbank 2010). On the other hand, governmental authorities are encouraged to provide the proper circumstances under which organizations could be more amenable to improvement through engaging with the organizations and developing optimal regulations, i.e., developing an ergonomic environment (Iberahim et al. 2016).

Customers are the key stakeholders and it is inarguable that customer needs and preferences must have a high priority. Customer focus allows organizations to design the right products/services, which leads to customer satisfaction and loyalty (Firbank 2010). Verma and Moran (Verma \& Moran 2014) proposed customer focus to sustain a CI culture.

\section{Operational Commitment}

Organizations that have a commitment towards operations management have the fundamental requirement for cultivating CI. This commitment is proven using a variety of tools and techniques in operations management. This is a place where some 
NPOs fail. Sometimes they think that these tools should be applied only in manufacturing industries, although they have been successful for years in the services and health sectors. This can be proven by the commitment to move forward toward automating possible operations, as mentioned in an interview:

".. the case is automatically directed to the social researcher, who does not have to be present in person. He works through his iPad. He receives a message with case details: location and mobile phone number .."

According to the data analysis and constant comparison with the literature, the characteristics that are associated with this theme include: the organization utilises defined tools for improvement, it benefits from feedback, its organizational structure is based on market needs, there are clear working procedures, and the organization's activities are based on planning and defined schedules (Lin et al. 2015; Levina et al. 2015; Mucai et al. 2014; Osunde et al. 2015; Gambescia \& Donnelly 2015; Plessis 2016; Nidhi Goyal 2016; Chowdhury et al. 2016; Hazen et al. 2016; Nowack 2015; Bechtel et al. 2015).

Operational Commitment means having a clear commitment to control and improve a process using certain tools and techniques (Shaked 2013). Bessant et al. (Bessant et al. 1994) suggested that the entirety of organization management should be transformed toward managing as a process, which could be strengthened by a supporting toolkit. Al-Tabbaa, Gadd, and Ankrah (AlTabbaa et al. 2013) had no doubt that 'managing for improvement' is in the spirit of CI. According to Bessant, Caffyn, and Gallagher (Bessant et al. 2001), CI development is essentially an evolutionary process, not a binary state. Process management underpins active CI implementation, which requires the use of scientific skills in decision-making and the adoption of a quality information system capable of producing precise and valid information (Lee et al. 2002). According to Firbank (Firbank 2010), CI is influenced by the degree of formalisation and professionalization throughout the organization. Verma and Moran (Verma \& Moran 2014) argued that process adjustment and improvement should be considered as a non-stop mission, one that needs to allow the proper infrastructure to keep processes improving continuously. Process management also needs to develop futuristic planning through implementing strategic performance management (Fryer \& Ogden 2014). Nguyen and Robinson (Nguyen \& Robinson 2015) observed that different types of organizational structures play roles in CI progress, and they believe that some national cultures have more suitable structures than others in terms of CI. According to Lodgaard et al. (Lodgaard et al. 2016), organizations must demonstrate management commitment to organizing and operating $\mathrm{CI}$ and prove this by using a variety of CI methods in addition to capturing and sharing knowledge. Good maintenance of equipment is one of the CI practices that is mentioned widely in CI literature and one that has an unarguable impact (Iberahim et al. 2016).

\section{Evaluation for Improvement}

Evaluation for Improvement is a non-stop journey toward excellence, there must be evaluation to assess the progress of this journey. This what could convince some notcontinuously-improving NPO leaders to adopt approaches to achieve this theme. Applying key indicators could remarkably help, as revealed in an interview:

".. we manage to contract with independent consulting and training centers, and they would give us the results before and after the training .."

According to the data analysis and constant comparison with the literature, the characteristics that are associated with this theme include: the organization adheres to performance standards, it implements improvements progressively, procedures are updated regularly, and to enhance this, channels of communications between employees are smooth and direct, and the organization allows employees flexibility in working hours (Blazovich 2014; Savolainen 2013; Vosloban et al. 2013; Schultz et al. 2015). 


\section{Summary and Conclusion}

The emergent filtered group of cultural aspects that influence $\mathrm{CI}$ had to be categorised to form a suitable way based on Schein, (1995), which classifies organizational problems into: internal integration and external adaptability. Solving this kind of problems are influenced by founders of an organization, who formulate the core mission of the organization, which may begin to modify to some extent its original assumptions (Schein 1995). While the internal integration problems are those that deal with group ability function as a group, which can be considered as socioemotional problems (Schein 1984). Schein (1984) believes that "solutions that an organization developed to solve both kind of problem when have worked well enough to be considered valid are, then, thought to new members as the correct way to perceive, think and feel in relation to these problems". The developed themes have been categorized by the most relevance based on Hofstede classification of organizational problem (Schein 1995), as shown below:

Table 2: Developed themes classified into organizational problems types

\begin{tabular}{|l|c|c|}
\hline $\begin{array}{c}\text { Cultural aspects to facilitate } \\
\text { CI }\end{array}$ & External adoption & $\begin{array}{c}\text { Internal } \\
\text { integration }\end{array}$ \\
\hline Driven by values & $\bullet$ & $\bullet$ \\
\hline Creative environment & & $\bullet$ \\
\hline Encouraged employees & & $\bullet$ \\
\hline External interactions & $\bullet$ & \\
\hline Operational commitment & & $\bullet$ \\
\hline Evaluation for improvement & $\bullet$ & $\bullet$ \\
\hline
\end{tabular}

The emergent aspects were found to be strongly connected with each other and remarkably associated with organizational culture. Therefore, its crucial to set the proper organizational settings that flourish and sustain CI. The review has highlighted the lack of empirical studies in the context of developing countries. Similarly, some sectors have not received sufficient research attentions. These lacks would offer researchers with opportunities to add their contributions to fill these knowledge gaps.

The empirical investigation has shown that the emergent aspects were found associated with Saudi national culture, which is a dominant component of Saudi society. The foundations have been shown to be more capable of adopting CI than the charities, i.e., foundation seem to be more professionally organized and struggling less with their financial stability, which allows them to concentrate more fully on operational excellence. However, some charities have shown a high commitment to $\mathrm{CI}$ and achieved a significant improvement, which make the themes that have emerged in the research available to both types of NPOs.

\section{Research Rigour and Ethical Issues}

Establishing rigour in action research that relies on qualitative data must be shown to demonstrate research quality (Coghlan \& Brannick 2014). Certain aspects of the rigour in qualitative research lead to its trustworthiness. These aspects, according to Guba and Lincoln (1994), include the credibility, transferability, dependability and confirmability that were typical of the data when they were collected and analysed, which all haven considered during conducting this research. In addition to the ethical issues have to be respected, which applied Cranfield university (2016) ethical principles that includes: includes: responsibility and accountability, integrity, intellectual freedom, respect and equality of opportunity, collegiality and sustainability. 


\section{Research Contribution}

The originality of this work results from the fact that, while Saudi Arabia is attracting intense interest from the international research community, little research has been done on CI practices there, in part because Saudi NPOs are hesitant to grant access to foreigner researchers. This study offers one of the first "inside views" of Saudi NPOs that contains reliable empirical data focusing particularly on cultivating a continuous $\mathrm{CI}$ culture.

\section{Limitations}

With regard to the issue of statistical generalizability (Yin 2009), the findings of this research would not be suitable for generalisation since the sample was not statistically representative. This is not a requirement when the objective is to understand social process (Mays \& Pope 1995). Further, quantitative research can address this issue.

\section{References}

1. Ahmed, P.K., Loh, A.Y.E. \& Zairi, M., 1999. Cultures for continuous improvement and learning. Total Quality Management, 10(4-5), pp.426-434.

2. Al Ahwal, M.S. et al., 2016. Religious beliefs, practices, and health in colorectal cancer patients in Saudi Arabia. PsychoOncology, 25(3), pp.292-299.

3. Akhtar, N., Azeem, S.M. \& Mustafa Mir, G., 2014. Impact of HRM Practices on Perceived Organizational Performance. International Journal of Academic Research, 6(5), pp.23-30.

4. Al-Tabbaa, O., Gadd, K. \& Ankrah, S., 2013. Excellence models in the non-profit context: Strategies for continuous improvement. International Journal of Quality \& Reliability Management, 30(5), pp.590-612.

5. Albassam, W.M. \& Ntim, C.G., 2017. The effect of Islamic values on voluntary corporate governance disclosure. Journal of Islamic Accounting and Business Research, 8(2), pp.182-202.
6. Alnassar, B.A., 2014. The Factors That Impact of e-Customer Relationship Management Performance (e-CRM) of Mobile Services in Jordan. Journal of Management Research, 6(3), p.199.

7. Alshammari, A.A. et al., 2014. An Exploratory Study on the Relationship between Organizational Innovation and Performance of Non-profit Organizations in Saudi Arabia. Procedia-Social and Behavioral Sciences, 129, pp.250-256.

8. Bechtel, N.T. et al., 2015. The Effects of the Temporal Placement of Feedback on Performance. Psychological Record, 65(3), pp.425-434.

9. Bessant, J. et al., 1994. Rediscovering continuous improvement. Technovation, 14(1), pp.17-29.

10.Bessant, J., Caffyn, S. \& Gallagher, M., 2001. An evolutionary model of continuous improvement behaviour. Technovation, 21(2), pp.67-77.

11.Bjerke, B. \& Al-Meer, A., 1993. Culture's Consequences: Management in Saudi Arabia. Leadership \& Organization Development Journal, 14(2), pp.30-35.

12.Blazovich, J.L., 2014. EMPLOYEEFRIENDLY COMPANIES AND WORK- LIFE BALANCE: IS THERE AN IMPACT ON FINANCIAL PERFORMANCE AND RISK LEVEL? Journal of Organizational Culture Communications and Conflict, 18(2).

13.Bouncken, R.B. \& Fredrich, V., 2016. Business model innovation in alliances: Successful configurations. Journal of Business Research, 69(9), pp.3584-3590.

14.Broekhuizen, E. \& Frericks, G., 1997. Empowering people in a five shift operation for continuous improvement. In 1997 IEEE International Symposium on Semiconductor Manufacturing Conference Proceedings (Cat. No.97CH36023). IEEE, pp. P7-10.

15.Burke, W.W., 2011. Organization Change: Theory and Practice, 
16.Calvasina, G.E., Calvasina, R. V. \& Calvasina, E.J., 2014. Social Media and Human Resource Staff: Legal, Policy and Practice Issues for Employers. Journal of Legal, Ethical \& Regulatory Issues, 17(2), pp.51-60.

17.Cárdenas, J.C.J. \& Mantilla, C., 2015. Between-group competition, intra-group cooperation and relative performance. Frontiers in behavioral neuroscience, 9(February), p.33.

18.Chang, D.S., Yeh, L.T. \& Liu, W., 2015. Incorporating the carbon footprint to measure industry context and energy consumption effect on environmental performance of business operations. Clean Technologies and Environmental Policy, 17(2), pp.359-371.

19.Charmaz, K., 2014. Constructing grounded theory, Sage.

20.Chowdhury, I. et al., 2016. Creating sustainable value through social business operations at the bottom of the pyramid.

21.Claeyé, F. \& Jackson, T., 2012. The iron cage re-revisited: Institutional isomorphism in non-profit organisations in South Africa. Journal of International Development, 24(5), pp.602-622.

22.Coghlan, D. \& Brannick, T., 2014. Doing action research in your own organization,

23.Council of Economic and Development Affairs, 2016. Saudi Vision 2030. , p.86. Available at: http://vision2030.gov.sa/download/file/fid /417.Cranfield, 2016. Ethics Code. , p.3.

24.Creswell, J.W., 1994. Research Design: Qualitative \& quantitativee approach.,

25.Dabhilkar, M., Bengtsson, L. \& Bessant, J., 2007. Convergence or National Specificity? Testing the CI Maturity Model across Multiple Countries. Creativity \& Innovation Management, 16(4), pp.348-362.

26.Dean, C.A., Fath, B.D. \& Chen, B., 2014. Indicators for an expanded business operations model to evaluate eco-smart corporate communities. Ecological Indicators, 47, pp.137-148.

27.Diamandescu, A. \& Ionita, V.-L., 2015. CALCULATION AND ANALYSIS IN THE EFFICIENCY OF APPLYING THE QUALITY MANAGEMENT SYSTEMS WITHIN INDUSTRIAL ORGANIZATIONS. Global Economic Observer, 3(2), pp.124-131.

28.Dixon, S., Meyer, K. \& Day, M., 2014. Building dynamic capabilities of adaptation and innovation: A study of microfoundations in a transition economy. Long Range Planning, 47(4), pp.186-205.

29.van Dun, D.H., Hicks, J.N. \& Wilderom, C.P.M., 2017. Values and behaviors of effective lean managers: Mixed-methods exploratory research. European Management Journal, 35(2), pp.174-186.

30.Eden, C. \& Huxham, C., 1996. Action Research for Management Research. British Journal of Management, 7(1), pp.75-86.

31.Fagan, P.F., 1996. Why Religion Matters: The Impact of Religious Practice on Social Stability. Backgrounder, 1064(1992), pp.130.

32.Faisal, T., Rahman, Z. \& Azam, M., 2011. Best practices of total quality management implementation in health care settings. Health Marketing Quarterly, 28(3), pp.232252.

33.Fenner-Crisp, P.A. \& Dellarco, V.L., 2016. Key elements for judging the quality of a risk assessment. Environmental Health Perspectives, 124(8), pp.1127-1135.

34.Firbank, O.E., 2010. Exploring the fit between organizational culture and quality improvement in a home-care environment. Health care management review, 35(2), pp.147-60.

35.Froese, F.J., Kim, K. \& Eng, A., 2016. Language, Cultural Intelligence, and Inpatriate Turnover Intentions: Leveraging Values in Multinational Corporations through Inpatriates. Management International Review, 56(2), pp.283-301. 
36.Fryer, K.J. \& Ogden, S.M., 2014. Modelling continuous improvement maturity in the public sector: key stages and indicators. Total Quality Management \& Business Excellence, 25(9-10), pp.1039-1053.

37.Gambescia, S.F. \& Donnelly, G.F., 2015. Managing and monitoring student 'issues' in higher education introduction. Journal of Allied Health, 44(3), pp.183-187.

38.Givens, R.J., 2012. The Study of the Relationship between Organizational Culture and Organizational Performance in NonProfit Religious Organizations. International Journal of Organization Theory \& Behavior, 15(2), p.239.

39.Glaser, B. \& Strauss, A., 1967. The discovery of grounded theory: strategies for qualitative.

40.Guba, E. \& Lincoln, Y., 1994. Competing paradigms in qualitative research. Handbook of qualitative ....

41.Harland, P. \& Nienaber, A., 2014. Trust and technology acceptance model: An experimental investigation concerning the idea contributor's acceptance of the organizational matchmaking process. Proceedings of PICMET'14.

42.Harris, M. \& Gibson, S., 2014. The Impact of Strategic Focus and Previous Business Experience on Small Business Performance. Journal of Small.

43.Hazen, B.T. et al., 2016. Back in business: operations research in support of big data analytics for operations and supply chain management. Annals of Operations Research, pp.1-11.

44.Hofstede, G., 1991. Cultures and organizations, London: McGraw-Hill.

45.Hofstede, G., Hofstede, G.J. \& Minkov, M., 2010. Cultures and Organizations, Software of the Mind: Intercultural Cooperation and its Importance for Survival,

46.Holliday, A., 2016. Doing and writing qualitative research, SAGE Publications.
47.Huang, X., Rode, J.C. \& Schroeder, R.G., 2011. Organizational structure and continuous improvement and learning: Moderating effects of cultural endorsement of participative leadership. Journal of International Business Studies, 42(9), pp.1103-1120.

48.Humphries, A. \& Gibbs, R., 2015. Enterprise Relationship Management: A Paradigm for Alliance Success. International Journal of Managing Projects in Business, 9(1), pp.234-236.

49.Iberahim, H. et al., 2016. Determinants of Sustainable Continuous Improvement Practices in Mail Processing Service Operations. Procedia - Social and Behavioral Sciences, 219, pp.330-337.

50.ICNL, 2016. Civic Freedom Monitor: Saudi Arabia. The International Center for Not-forProfit Law. Available at: http://www.icnl.org/research/monitor/sau diarabia.html [Accessed December 6, 2017].

51.de Jager, B. et al., 2004. Enabling continuous improvement: a case study of implementation. Journal of Manufacturing Technology Management, 15(4), pp.315-324.

52.Jurisch, M. \& Palka, W., 2014. Which capabilities matter for successful business process change? Business Process Management Journal, 20(1), pp.47-67.

53.Kabasakal, H. \& Bodur, M., 2002. Arabic cluster: A bridge between east and west. Journal of World Business, 37(1), pp.40-54.

54.Keim, A.C. et al., 2014. Why do employees worry about their jobs? A meta-analytic review of predictors of job insecurity. Journal of Occupational Health Psychology, 19(3), pp.269-290.

55.King Khalid Foundation, 2018. Saudi Nonprofit Trends, Riyadh, Saudi Arabia.

56.Kistruck, G.M. et al., 2015. Cooperation Vs Competition: Alternative Goal Structures for Motivating Groups in a Resource Scarce Environment. Academy of Management Journal, 59(4), p.amj.2014.0201. 
57.Lee, S. et al., 2002. Assessing the factors influencing continuous quality improvement implementation: Experience in Korean hospitals. International Journal for Quality in Health Care, 14(5), pp.383-391.

58.Levina, E., Pyrkova, G. \& Zakirova, C., 2015. Socio-Economic Systems Strategic Development Managing. Journal of.

59.Lin, G., Hsieh, P. \& Chou, C., 2015. Crucial Factors for Success in Taiwan's Cloud Information Services Industry. International Journal of.

60.Lodgaard, E. et al., 2016. Barriers to Continuous Improvement: Perceptions of Top Managers, Middle Managers and Workers. In Procedia CIRP. pp. 1119-1124.

61.Lussier, R.N. \& Corman, J., 2015. THERE ARE FEW DIFFERENCES BETWEEN SUCCESSFUL AND FAILED SMALL BUSINESSES. Journal of Small Business Strategy, 6(1), pp.21-34.

62.Mays, N. \& Pope, C., 1995. Qualitative research: Observational methods in health care settings. BMJ (Clinical research ed.), 311(6998), pp.182-184.

63.McMurray, A. \& Muenjohn, N., 2016. the Impact of Leadership on Workplace Innovation in Thai and. The Journal of Developing Areas, 50(5).

64.MLSD, M. of L. and S.D., 2017. Ministry of Labour and Social Development. Available at: http://mlsd.gov.sa.

65.Montagu, C., 2010. Civil society and the voluntary sector in Saudi Arabia. The Middle East Journal, 64(1), pp.67-83.

66.Mucai, G.P., Wanjiku, K.F. \& Murigi, L.M., 2014. Strategic Organisation Development and Project Performance of Not for Profit Organisations' In Isiolo Sub-County-Kenya. International Review of, (1997), pp.13161324.

67. Murante, A.M. et al., 2014. Does feedback influence patient - professional communication? Empirical evidence from Italy. Health Policy, 116(2-3), pp.273-280.
68.Nguyen, P.A. \& Robinson, A.G., 2015. Continuous improvement in Vietnam: unique approaches for a unique culture. Journal of Asia Business Studies, 9(2), pp.195-211.

69.Nidhi Goyal, 2016. Employee Engagement: the Key To Improving Performance. Golden research thoughts, 5(11), pp.89-96.

70.Nowack, K.M., 2015. 360 Feedback: From Insight to Improvement. Public Manager, 44(2), pp.20-23.

71.Oliver, J., 2009. Continuous improvement: role of organisational learning mechanisms. International Journal of Quality \& Reliability Management, 26(6), pp.546-563.

72.Osunde, C. et al., 2015. Management problems and practices: India and Nigeria. Advances in Management, 8(1), pp.9-14.

73.Ovidiu-Iliuta, D., 2014. The Link between Organizational Culture and Performance Management Practices: a Case of it Companies from Romania. Annals of the University of Oradea, Economic Science Series, 23(1), pp.1156-1163.

74.Patterson, T., Nicholls, D.L. \& Long, J.W., 2015. Research and development portfolio of the Sustainability Science Team national sustainable operations USDA Forest Service,

75.Pew Research Center, 2017. The Changing Global Religious Landscape,

76.Phipps, S.T.A., Prieto, L.C. \& Ndinguri, E.N., 2013. Understanding the Impact of Employee Involvement on Organizational Productivity: The Moderating Role of Organizational Commitment. Journal of Organizational Culture, Communications and Conflict, 17(2), pp.107-121.

77.Plessis, A. du, 2016. The contribution of policies, procedures and rules for successful suggestion systems in organisations: some research findings. Journal of Community Positive Practices.

78.Pun, K.-F.K.K.-F., 2001. Cultural influences on total quality management adoption in Chinese enterprises: An empirical study. 
Total Quality Management, 12(3), pp.323342 .

79.Rama Devi, V. \& Phanindra, R., 2014. Employees ' Perception of Effectiveness of Training and Development in Private Sector Banks. Advances in Management, 7(4), pp.1621.

80.Ramakrishnan, R., 2015. A Business Process view of Software: An effective measurement model to assess the operations readiness of software under construction. INCOSE International Symposium.

81.Rodell, J.B. et al., 2016. Employee Volunteering: A Review and Framework for Future Research. Journal of Management, 42(1), pp.56-84.

82.Sackmann, S. a., 1991. Uncovering Culture in Organizations. The Journal of Applied Behavioral Science, 27(3), pp.295-317.

83.Salamon, L.M. et al., 2013. The State of Global Civil Society and Volunteering: Latest findings from the implementation of the UN Nonprofit Handbook,

84.Savolainen, T., 2013. Change Implementation in Intercultural Context: A Case Study of Creating Readiness to Change. Journal of Global Business Issues, 7(2), pp.5158.

85.Schein, E.H., 1984. Coming to a New Awareness of Organizational Culture. Sloan Management Review, 25(2), p.3.

86.Schein, E.H., 1995. The Role of the Founder in Creating Organizational Culture. Family Business Review, 8(3), pp.221-238.

87.Schultz, M.D. et al., 2015. Managing the Effects of Social Media in Organizations. SAM Advanced Management Journal (07497075), 80(2), pp.42-47.

88.Shaked, D., 2013. Strength-Based Lean Six Sigma: Building Positive and Engaging Business Improvement,

89.Shortell, S.M. et al., 1995. Assessing the impact of continuous quality improvement/total quality management:
Concept versus implementation. Health Services Research, 30(2), p.377.

90.Starks, H. \& Trinidad, S.B., 2007. Choose your method: a comparison of phenomenology, discourse analysis, and grounded theory. Qualitative health research, 17(10), pp.1372-1380.

91.Testani, M. V \& Ramakrishnan, S., 2012. Lean leadership readiness for change: A methodology for lean change readiness and continuous improvement. In 62nd IIE Annual Conference and Expo 2012. pp. 2138-2147.

92.The World Bank, 2018. Saudi Arabia GDP. Available at: http://data.worldbank.org/country/saudiarabia [Accessed October 19, 2016].

93.Transparency International, 2017. Corruption Perceptions Index. Available at: https://www.transparency.org/news/featur e/corruption_perceptions_index_2017 [Accessed February 25, 2018].

94.USNews, 2018. Best Countries 2018.

95.Vaijayanthi, P. \& Shreenivasan, K., 2014. Case Study: Organizational Culture: An Antecedent to Employee Involvement-A Pragmatic Study. Advances in Management.

96.Vasavada-Oza, F., 2016. Promoting Organizational Brands as Desirable Employers Through Company Websites: A Study of Three Indian IT Companies. IUP Journal of Brand.

97.Verma, P. \& Moran, J.W., 2014. Sustaining a quality improvement culture in local health departments applying for accreditation. Journal of Public Health Management and Practice, 20(1), pp.43-48.

98.Vietor, R.H.K. \& Sheldahl-Thomason, H., 2018. Saudi Arabia: Vision 2030,

99.Vosloban, R., Vrabiuta, M. \& Aldea, R., 2013. Confronting the Consequences of a Permanent Changing environment. Manager Journal. 
100. Wick, J., 2014. implementing change: involving employees to improve outcomes. The Consultant Pharmacist $\AA$.

101. Yin, R.K., 2009. Case Study Research: Design and Methods,
102. Zhang, H. \& Cao, D., 2014. Impact of job security on employees' innovative behavior: The mediating effect of perceived organizational support. Journal of Nanjing University. 